\title{
Western Eurasian ancestry in modern Siberians based on mitogenomic data
}

\author{
Miroslava Derenko ${ }^{1 *}$, Boris Malyarchuk', Galina Denisova', Maria Perkova ${ }^{1}$, Andrey Litvinov ${ }^{1}$, Tomasz Grzybowski $^{2}$, \\ Irina Dambueva ${ }^{3}$, Katarzyna Skonieczna², Urszula Rogalla², losif Tsybovsky ${ }^{4}$ and llya Zakharov ${ }^{5}$
}

\begin{abstract}
Background: Although the genetic heritage of aboriginal Siberians is mostly of eastern Asian ancestry, a substantial western Eurasian component is observed in the majority of northern Asian populations. Traces of at least two migrations into southern Siberia, one from eastern Europe and the other from western Asia/the Caucasus have been detected previously in mitochondrial gene pools of modern Siberians.

Results: We report here 166 new complete mitochondrial DNA (mtDNA) sequences that allow us to expand and re-analyze the available data sets of western Eurasian lineages found in northern Asian populations, define the phylogenetic status of Siberian-specific subclades and search for links between mtDNA haplotypes/subclades and events of human migrations. From a survey of 158 western Eurasian mtDNA genomes found in Siberia we estimate that nearly $40 \%$ of them most likely have western Asian and another 29\% European ancestry. It is striking that 65 of northern Asian mitogenomes, i.e. 41\%, fall into 19 branches and subclades which can be considered as Siberian-specific being found so far only in Siberian populations. From the coalescence analysis it is evident that the sequence divergence of Siberian-specific subclades was relatively small, corresponding to only 0.6-9.5 kya (using the complete mtDNA rate) and 1-6 kya (coding region rate).
\end{abstract}

Conclusions: The phylogeographic analysis implies that the western Eurasian founders, giving rise to Siberian specific subclades, may trace their ancestry only to the early and mid-Holocene, though some of genetic lineages may trace their ancestry back to the end of Last Glacial Maximum (LGM). We have not found the modern northern Asians to have western Eurasian genetic components of sufficient antiquity to indicate traces of pre-LGM expansions.

Keywords: Complete mitochondrial genomes, Western Eurasian mtDNA lineages, Phylogeny, Western Asian ancestry, European ancestry, Northern Asia

\section{Background}

The peopling of northern Asia by anatomically modern humans probably began more than $40 \mathrm{kya}$, with the first evidence of human occupation in the Altai region, suggesting the southern mountain belt of Siberia and Middle Siberian plateau was the likely route for this pioneer settlement of northern Asia. Archaeological data definitely supports colonization of the Lake Baikal region in the southern Siberia since the Upper Paleolithic [1-4], however, little is known whether there was biological continuity from around $40 \mathrm{kya}$ to the present. East Asian craniometric features thought to have been derived from early modern

\footnotetext{
* Correspondence: mderenko@mail.ru

${ }^{1}$ Institute of Biological Problems of the North, Russian Academy of Sciences, Magadan, Russia

Full list of author information is available at the end of the article
}

East Asians exist in human remains from the Afontova Gora-2 site in upper Yenisei basin and indicate that East Asians moved into southwestern Siberia by 21 kya or even earlier [3]. Yet, the Upper Paleolithic artifacts from the Mal'ta site in the Angara River basin in south-central Siberia (radiocarbon dated to about 23 kya) have been found in association with skeletal remains that bear similar morphology with contemporary anatomically modern humans teeth from Europe thus providing the evidence for links between Siberia and the West during the Upper Paleolithic [1,2,5]. The prevalence of European craniological features among steppe zone inhabitants of Tuva, Altai, and Khakassia of southern Siberia, and even western Mongolia became the most significant since the Bronze Age or even earlier [3,6]. The boundary of the eastern European influence is clearly fixed at Lake Baikal. To the east of 
Baikal no paleoanthropological findings bear any traces of European admixture [3].

Over the past few years, a number of notable genetic studies on ancient Siberians were conducted. Molecular data suggests that mitochondrial genome of 24 kya old individual from the Mal'ta site belongs to haplogroup U, which has been found at high frequency among Upper Paleolithic and Mesolithic European hunter-gatherers populations, thus testifying a connection between preagricultural Europe and Upper Paleolithic Siberia [7]. The western Eurasian mtDNA haplogroup U5a lineages were also revealed in two Neolithic Angara River basin cemetery populations - Kitoi (dated to 7250-6040 years ago) and the Serovo-Glazkovo (dated to 4960-3590 years ago), though the majority of their mtDNAs were of eastern Eurasian ancestry [8]. Notably, the significant influx of western Eurasian mtDNAs into gene pools of ancient Siberians is observed from the early Bronze and Iron Ages (from about 3500 years BC to 200 years AD), thus attesting the eastward migrations of Kurgan people alongside the Eurasian steppe belt, extending from Europe to Manchuria [9-11]. It should be noted however that no genetic data between the Iron Age and today are currently available for Siberian populations.

Evidence from genome-wide autosomal SNPs genotyping testified the presence of both eastern and western Eurasian lineages in gene pools of modern populations of Siberia, a pattern that definitely reflects a complex history of population movements and interactions since Paleolithic times [12-14]. Genome-wide analysis revealed that the genetic landscape of Siberian populations is characterized by two main components unevenly distributed across the studied populations and mixed with other genetic components shared by European or East Asian populations. Admixture dating confirmed that the variable European component seen in the central and northeastern Siberian populations is a result of recent admixture, whereas populations of Altai region of southern Siberia had the highest proportion of European component and the most ancient European admixture dating from the Siberian populations studied [14].

Despite the potential of genomic studies, the particular value of full mitogenome sequencing should be stressed, as the fine genealogical resolution of full mitogenomes together with sufficient sampling can provide a detailed reconstruction of genetic history both for specific lineages and populations in general [15-20]. Thus, for example, the present-day variation of haplogroups $\mathrm{C}$ and $\mathrm{D}$, the most frequent throughout northern, eastern, central Asia and America, suggests that these mtDNA clades expanded long before the LGM (dated to 19-26.5 kya), with their oldest lineages being present in the eastern Asia. Unlike in eastern Asia, most of the northern Asian variants began the expansion after the LGM, thus pointing to postglacial recolonization of northern Asia [17]. Moreover, the results showed that both haplogroups were involved in migrations from eastern Asia and southern Siberia to eastern and northeastern Europe likely during the middle Holocene. In turn, western Eurasian haplogroups found in gene pools of southern Siberians demonstrate an obvious link between populations of Siberia and those of western Asia, the Caucasus, and eastern Europe, with coalescence time estimates suggesting their post-LGM flows from the west [15].

Unfortunately, such issues as timing, origin, and routes of western Eurasian migrations into Siberia remain unresolved mainly due to incompleteness of current complete mtDNA data set. It should be noted that the human mtDNA phylogeny does not equally represent different human populations but it is biased towards representatives of northern and central Europe, so some crucial gaps in certain geographic regions exist. This affects phylogeny of many western Eurasian haplogroups, whose eastern and southern European, Near Eastern and central Asian components are poorly represented. Notwithstanding, recently published comprehensive data set on complete mtDNA variation in Iranians, representative of the majority of the provinces and the ethnic groups [21], as well as global phylogeny reconstruction of western Eurasian haplogroups JT, N1, N2, X, U4, U5, and U8 [22-27] allow us to expand and re-analyze the available data sets of western Eurasian complete mtDNA lineages found in northern Asian populations, reaching 158 mitogenomes (including 85 novel mtDNAs), define the phylogenetic status of Siberian-specific subclades and search for links between mtDNA haplotypes/subclades and events of human migrations.

\section{Results}

It is known that the majority of northern Asian populations exhibit a significant contribution of the western Eurasian mtDNA component, represented by numerous lineages belonging to major haplogroups $\mathrm{H}, \mathrm{HV}, \mathrm{R} 1, \mathrm{R} 2, \mathrm{JT}, \mathrm{U}, \mathrm{N} 1$, $\mathrm{N} 2 \mathrm{a}, \mathrm{W}$, and X. Among them, haplogroups H, J, and U are the most frequent. The proportion of western Eurasian lineages is considerably higher in western $(21 \%-70 \%)$ and southern (up to 35\%) parts of Siberia (reaching their maximum frequencies in populations of Kets, Khanty, Mansi, Altaians and Altaian Kazakhs) than in central (up to $10 \%$ ) and northeastern (up to 2\%) parts of Siberia (Additional file 1 and Additional file 2).

To elucidate the origin of western Eurasian lineages found in mitochondrial gene pools of northern Asians we have analyzed 158 Siberian mitogenomes belonging to different western Eurasian haplogroups, including 85 novel complete mtDNA sequences. The phylogenetic relationships of the 158 western Eurasian mitogenomes found in Siberian populations are depicted in detail in Additional file 3. Information concerning the ethnic origin of each mitogenome, haplogroup affiliation, age 
estimates, specificity and putative origin of haplogroups and subclades are provided in Additional file 4.

Haplogroup U (5.1\% overall) is represented in Siberia by almost all major clades, except for U6 and U9 predominant in northern African/Near Eastern populations. Haplogroups U1 and U7 are very rare in Siberia, but characteristic of western Asian region. Both haplogroups are extremely rare in populations of eastern Siberia (about 0.1\%) [15]. In western Siberia, frequency of U1 accounts for $0.2 \%$, but haplogroup U7 is present at relatively high frequency $(\sim 7.3 \%)$ in Khanty and Mansi gene pools $[28,29]$. We sequenced one U1 and one U7 complete mtDNA genomes revealed in Buryats and compared them with all published complete sequences, including some Siberian haplotypes available in GenBank. This analysis shows that Siberian lineages belong to subclades U1a1a, U7a2, U7a3 and to a novel subclade U7a4b defined by transition at np 16150, all having a potential western Asian origin (Additional file 5).

Phylogeographic studies have shown that haplogroup U2e is present mainly in western Eurasian populations at a frequency of $1 \%$ on average, varying from $0.9 \%$ in Europe to $1.7 \%$ in western Asia [30]. In Siberia, frequency of U2e is about $0.9 \%$, but in some Altaian populations (such as Altaian-Kizhi, Teleuts and Telenghits) this haplogroup reaches higher than the average frequencies (up to $3 \%$ ) $[15,31,32]$. However, the Altaian U2e haplotypes are defined by transitions at nps 16214 and 16258 and seem to be unique for Altaians. We have checked this diagnostic motif in all available published data sets on control region mtDNA variation and found similar haplotypes, albeit bearing only 16214 transition, only in populations of northern Caucasus (such as Adygei and Balkars) [33,34].

Until now, the phylogeny of haplogroup U2e has been only partially resolved at the level of complete mtDNAs, especially for eastern European populations. To provide new information concerning the molecular dissection of haplogroup U2e we have completely sequenced 34 samples representing populations of eastern Europe (Russians, Belarusians, Ukrainians, Poles, and Slovaks) and Siberia (Barghuts and Altaian Kazakhs) (Additional file 5). Phylogenetic analysis based on 75 U2e mitogenomes has shown that three clades can be recognized - U2e1, U2e2 and U2e3. We redefined clade U2e2 by the only transition at np 8473 and identified four novel subclades - U2e1a1c, U2e1b1a, U2e1b3 and U2eli. Analysis demonstrates that Barghut individual together with Russian form subclade U2e1b3, whereas Tubalar and Altaian Kazakh individuals belong to subclade U2eli, defined by two mutations in control region (at nps 16214 and 16258) and four mutations in the coding region (at nps 2626, 5814, 13914 and 14587). As have already mentioned this subclade appears to be unique, being found only in the Altai region populations. Unfortunately, its molecular dating is impossible because only two identical mitogenomes were sequenced to date. Meanwhile, a coalescence time estimate of the whole clade U2e1 corresponds to 16.3-19.4 kya, suggesting a relatively early arrival of the U2e1i founder into the Altai region. Note however that the actual appearance of this mtDNA lineage in the Altai could happen much later.

Haplogroup U3 is typical of the Near East and of the populations from surrounding areas. According to the mtDNA control region data, it is suggested that the U3 was among the main Neolithic founder clades in Europe [33]. However, the reconstruction of complete mtDNA phylogeny and molecular dating of haplogroup U3 subclades is still required, partly due to scarcity of the published complete mtDNA sequences from eastern European populations. Therefore, we provide here new information concerning the 18 mitogenomes of eastern Europeans (Russians, Belarusians, Poles and Czechs), and compare these data with those obtained from western Eurasian populations. Frequency of haplogroup U3 in Siberian populations is very low $(0.7 \%$; $[15])$, so we sequenced the only mitogenome of Altaian individual and found that it together with Hungarian mtDNA belongs to a new subclade U3b2c, for which it is difficult to locate a source now (Additional file 5).

In general, in the phylogenetic tree represented by 81 western Eurasian U3 mitogenomes, we identified two clades (U3a'c and U3b), with many already known in accordance with the PhyloTree data base subclades, except for two new ones - U3b1c and U3b2c. Moreover, phylogeographic analysis along with molecular dating allowed us to recognize two subclades (U3a1 and U3b1b), both presumably originated in Europe relatively recently on the basis of western Asian founders. Subclade U3a1 dated to about 6.4 kya has European-wide distribution, and subclade U3b1b dated to about 2.3 kya seems to be specific for Slavic populations only (Additional file 5).

Haplogroup U4 is one of the most frequent in populations of eastern Europe, the Volga-Ural region and western Siberia [22,28,29,35-37]. This haplogroup reaches the relatively high frequencies (up to $18 \%$ ) in aboriginal populations of the Altai-Sayan region - in Altaians and Khakassians $[15,19,31,32,38]$. To reconstruct phylogeny of Siberian U4-mitogenomes we sequenced 10 mtDNAs of Buryats, Kalmyks, Altaian Kazakhs, Altaians, Shorians, Khakassians and Tuvinians, combined them with 14 mitogenomes retrieved from GenBank (from populations of Yakuts, Tubalars, Mongols, Nganasans, Khants and Mansi) and reconstructed phylogenetic tree based on variation of 125 mitogenomes (Additional file 5). As can be seen, three Siberian lineages fall into eastern European subclades $\mathrm{U} 4 \mathrm{a} 2 \mathrm{a}$ and U4d2b, and four - to subclade U4b1b1 having a potentially western Asian source. The remaining northern Asian U4 mtDNAs belong to subclades U4a*, U4a1*, 
U4a1e, U4a1d, U4b1a4, U4b1*, U4d2*, U4d2a, U4b3a, which origin remains uncertain. Molecular dating of subclades containing Siberian lineages has shown that overwhelming majority of them dates back to the time that does not exceed 6 kya (3.5-3.9 kya for U4a1d, 1.9 kya for U4b1a4, 3.7-5.9 kya for U4b1b1c, 2.6-4.6 kya for U4b3a, 1.5-4.3 kya for U4d2a, 1.5-5.2 kya for $\mathrm{U} 4 \mathrm{~d} 2 \mathrm{~b})$. Only two haplotypes identified as belonging to the U4a* (in Mansi) and U4b1* (in Tubalars) cannot be dated, but the upper bounds defined by age of the parental clade (11.2-13.9 kya for U4a and 17.2-18.8 kya for U4b1) are within the Upper Paleolithic time scale.

The most ancient European haplogroup U5 dated to $\sim 25-30$ kya is represented in northern Asia by both U5a and U5b clades at frequencies of $0.7 \%$ and $0.6 \%$, respectively [15]. To identify U5 haplotypes and clarify their origin we compared 14 complete mitogenomes (including 11 own) from Siberian populations with 225 mtDNAs originating from different Eurasian populations and found that almost all of them belong to already known U5 subclades. The only subclade U5a2a1f harbored previously non-reported diagnostic mutation at np 709 (Additional file 5). Interestingly, Siberian U5b mtDNAs clustered into subclade U5b1b1a, characterized by "Saamispecific" mutation at np 16144, together with Saami, Finns, Russians, Belarusians and Slovaks. Molecular dating results (3.7-4.9 kya) suggest a relatively recent arrival of the U5b1b1a lineage into Siberia.

Haplogroup U8 is represented by rare clade U8a and U8b, consisting of clades U8b1 and K. U8a is more frequent in Europe, while U8b1 occurs beyond Europe, as it is found in western Asia, the Caucasus and northern Africa. Clade $\mathrm{K}$ is more widespread and abundant covering the U8a and U8b1 ranges [26]. In northern Asia, the majority of the U8 mtDNAs belongs to haplogroup $\mathrm{K}$ ( $1 \%)$, whereas U8a and U8b1 accounts for only $0.2 \%$ and $0.1 \%$, respectively. In order to identify Siberian U8 lineages we generated $10 \mathrm{~K}$ and $1 \mathrm{U} 8 \mathrm{a}$ mitogenomes of aboriginal Siberians and, in addition, $8 \mathrm{U} 8 \mathrm{a}$ and $8 \mathrm{~K}$ complete mtDNAs of eastern Europeans (Russians, Poles, Slovaks, Czechs) and compared them with the complete U8 phylogeny, comprising now 971 whole mitogenomes, recently published by Derenko et al. [21] and Costa et al. [26].

Clade U8a phylogeny demonstrates that our Buryat individual together with eastern Europeans (Russians, Finns and Swedes) belongs to subclade U8a1a1b1. The addition of Polish mtDNA (P14) to the tree gives a new branching point for U8a2, defined now by transitions at nps 827 and 1700. Most surprisingly, by analyzing Siberian K sequences in the context of published Eurasian mtDNAs, we found eight subclades including five new K1a17b, K1a3b, K1a32, K1b2a2b and K2a5b, two of which (K1a17b and K1a32) seem to be Siberian-specific, being found so far only in Buryats and Khamnigans (Figure 1, Additional file 5).

Using the whole-mitogenome data, we can suppose that Siberian haplogroup K1a17b, K1a3b, and K2a5b lineages have a potential western Asian ancestry, whereas K1b2a2b, K1b2a2*, and K2a3* mitogenomes most likely trace their ancestry within eastern Europe.

In general, out of 58 northern Asian U mitogenomes sequenced to date $25 \%$ most likely have eastern European ancestry, and another $22 \%$ have a potential western Asian origin.

\section{Haplogroup H}

The control region mtDNA distribution for all northern Asian lineages $(\mathrm{n}=5568)$, summarized in Additional file 1 , indicates that the overall frequency of haplogroup $\mathrm{H}$ in the northern Asian data base is $3.9 \%$, but this varies from $0.3 \%$ in Evens to $14 \%$ in Khanty and Mansi. As far as haplogroup $\mathrm{H}$ carries only a weak phylogenetic signal in the control region, we cannot emphasize the position

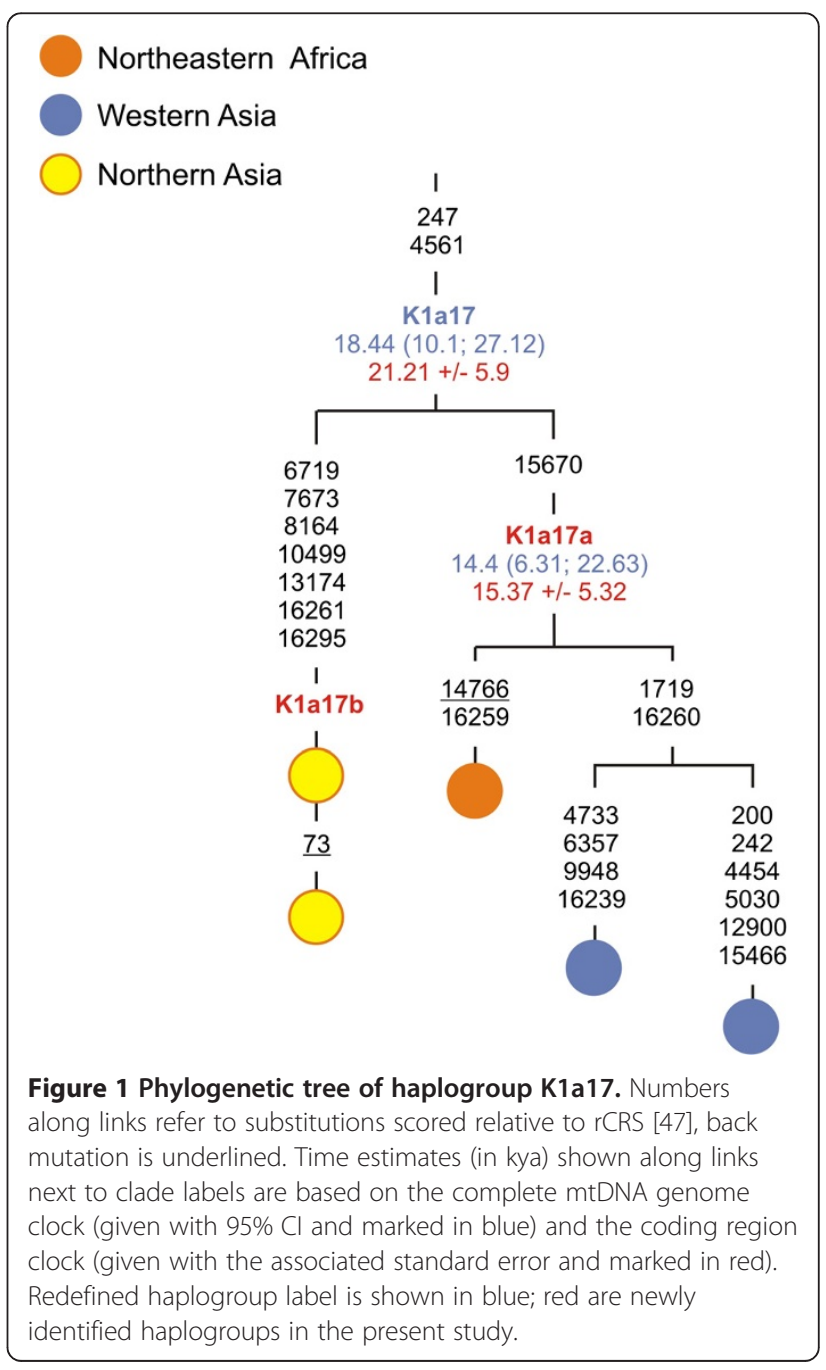


of all Siberian haplogroup $\mathrm{H}$ lineages in the control region mtDNA data base. We have therefore estimated the fraction of Siberian lineages within haplogroup $\mathrm{H}$ that can be allocated to a European or western Asian sources using the 55 Siberian mitogenomes which are currently available (Additional file 4). As can be seen, at least a quarter of Siberian mtDNAs can be assigned to specific subclades within predominantly European haplogroups H1and H3 in the global mitogenome tree (H1a3b, H1b1a, H1b3, H1g1, H1h1, H1*, H1ca, H3g3, and H3*), with another quarter allocated to H2a1a*, H2b, H5a1, H6alb, H6a1*, H11a1, and H11a2a2. Of these, only H2b, H3g3, and $\mathrm{H}^{*}$ can plausibly be ascribed as having a potential western Asian origin.

There are several minor lineages within haplogroup $\mathrm{H}$ (H15a1*, H15a1a1a, H15b, H20a, H35*, and H97), which again nest with western Asian lineages, and further minor lineages belonging to $\mathrm{H} 27 \mathrm{a}, \mathrm{H} 7 \mathrm{~b}$ and $\mathrm{H} 34$, which appear to have arisen in Europe or even in eastern Europe. There is, furthermore, an mtDNA from Buryat individual identical to Druze mitogenome, falling alongside with an Italian into haplogroup H7c1, which again most likely derives from a European source. There are also mtDNAs from a single Altaian and Altaian Kazakh, belonging to haplogroup $\mathrm{H}^{*}$, for which it is difficult to locate a source as these branches emerge directly from the root of haplogroup H. H49 also remains ambiguous, though its $\mathrm{H} 49 \mathrm{c}$ branch can be considered as Siberian-specific being found in three Yakuts and one Buryat individual only (Additional file 5).

Another haplogroup, H8b1 is also found solely in Siberians, and it falls into two distinct sub-clades, H8b1a and H8b1b, with almost the same coalescence age estimated as 0-3.5 kya and 1.3-3 kya, respectively (Figure 2). If we regard $\mathrm{H} 8$ as potentially having a Near Eastern and Caucasus source (as has been suggested in [39] based on the mtDNA hypervariable region 1 (HVS 1 ) variability data), we may assume that $\mathrm{H} 8 \mathrm{~b} 1$ might have arose in situ in southern Siberia after the arrival of the H8b1 founder from somewhere else in the Near East/Caucasus region.

Thus, only $16 \%$ of northern Asian haplogroup $\mathrm{H}$ lineages are difficult to assign, but at least $42 \%$ are likely of European and another $42 \%$ of western Asian origin.

\section{Haplogroups J and T}

Haplogroup J comprises 2.1\% of the northern Asian control-region data base with frequencies ranging from $0.6 \%$ in Yakuts to $12 \%-15 \%$ in Khanty and Mansi. To resolve the haplogroup status and potential origin of northern Asian J-lineages we have analyzed twelve complete mitogenomes which were compared to a global haplogroup J phylogeny reconstructed recently by Pala et al. [25]. There is a sequence shared between Buryat and Italian nesting within western Asian J1b1b1 subclade, and there is also a single Altaian sequence clustering within Iranian-specific subclade J1b1b1a with coalescence age estimated as 6.0-6.6 kya (Additional file 5). Two other Siberian mitogenomes found in Khanty and Mansi belong to J1d6a which again most likely derives from a western Asian source. On the other hand, two Yakut mitogenomes belong to $\mathrm{J} 1 \mathrm{c} 5^{*}$, and another to J2a2c1 of likely European origin. The remaining four Siberian J mtDNAs can be assigned to a new J2a2b3 subgroup for which it is difficult to locate a source as these lineages nest together with both northern African-specific J2a2b1 subclade and J2a2b2 lineage of uncertain ancestry originated from the United Kingdom. There is also a single Buryat mitogenome which together with a related sequence from Italy belongs to subclade J1c10a with uncertain origin (Additional file 4 and Additional file 5).

The haplogroup $\mathrm{T}$ lineages (1\% overall) are more difficult to assign, but at least single Khamnigan mtDNA belonging to T2a1a1b is likely of European origin, whereas the new T2g1a1 subclade specific to Yakuts may have western Asian origin (Additional file 5).

\section{Other minor western Eurasian mtDNA lineages in northern Asian gene pool}

There are numerous other minor western Eurasian mtDNAs in the Siberian mtDNA pool, as can be seen in the control region data base (summarized in Additional file 1), relatively few of which have been subjected to whole-mitogenome sequencing.

The haplogroup HV lineages comprise a number of diverse mtDNAs with overall frequency $\sim 0.6 \%$ in the northern Asian control region data base, and eleven of them are completely sequenced to date (Additional file 5). The lineages with a potentially Near Eastern source include HV1, HV12b1 and HV13a. The Siberian-specific HV1a1a1 and HV1a1a2 mitogenomes date to 1.5-2.6 kya and nest within a cluster of Near Eastern/Caucasus HV1a1a lineages dating to 6-6.7 kya (Figure 3, Additional file 5). There are also single haplogroup HV6 and HV9 lineages with a probable European origin.

The haplogroup W3 lineages all belong to a single subclade W3a1d with a probable European origin. The haplogroup I lineages clearly nest within haplogroup I4a for which an origin cannot be estimated at present.

There are several haplogroup N1a1a1a1 lineages clustering within Siberian/European subclade N1alalala with coalescence age estimated as 9.7-10.3 kya (Additional file 5). The control region data base showed that the N1alalala clade, characterized by 16189 in HVS1, is found in Kazakhstan, Altai and Baikal regions of southern Siberia and eastern Europe, so its origin remains uncertain [40]. There is single Buryat mtDNA belonging to redefined haplogroup N1a1bla1 of likely western Asian origin. 


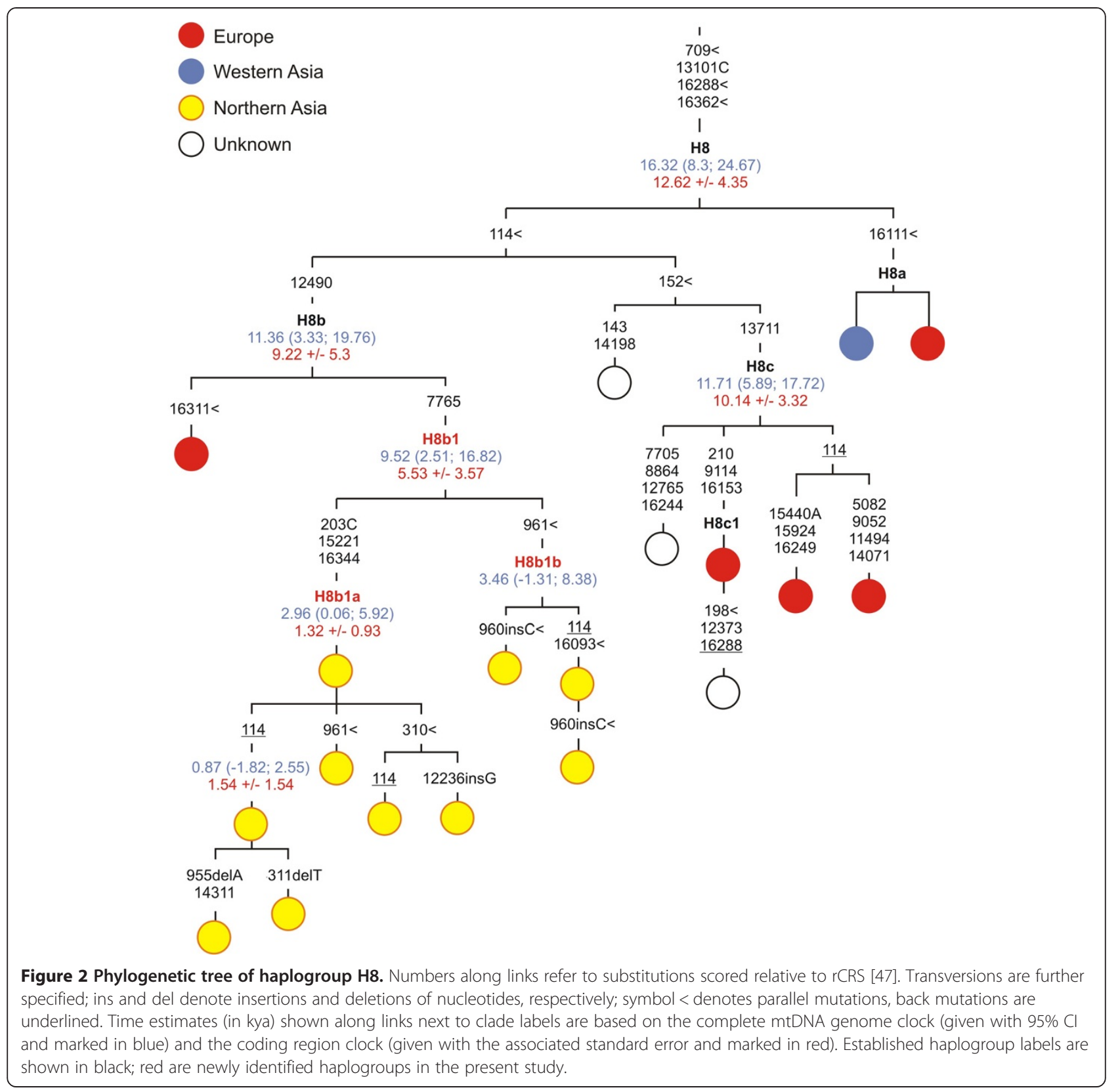

The haplogroup $\mathbf{X}$ mtDNAs found in Altai and Baikal regions of southern Siberia all belong to X2e2a1 subclade nesting within X2e2a which includes lineages from Near East and Caucasus, pointing thus to western Asian ancestry of Siberian X2e2a1 lineages (Additional file 5).

Overall, from a survey of 158 western Eurasian mtDNA genomes found in Siberia we estimate that $37 \%$ of them most likely have western Asian and another 29\% European ancestry, whereas 34\% remain ambiguous. It is striking that 65 of northern Asian mitogenomes, i.e. $\sim 41 \%$, fall into 19 branches and subclades which can be considered as Siberian-specific being found so far only in Siberian populations. From the coalescence analysis it is evident that the sequence divergence of Siberian-specific subclades was relatively small, corresponding to only 0.6-9.5 kya (using the complete mtDNA rate) and 1-6 kya (coding region rate), thus implying a Holocene origin and expansion of these lineages in northern Asia (Table 1).

\section{Discussion}

In the last few years, the availability of a growing number of complete mitogenomes (20,666 in PhyloTree data base; released on February 19, 2014) has considerably improved our knowledge on the worldwide human mtDNA 


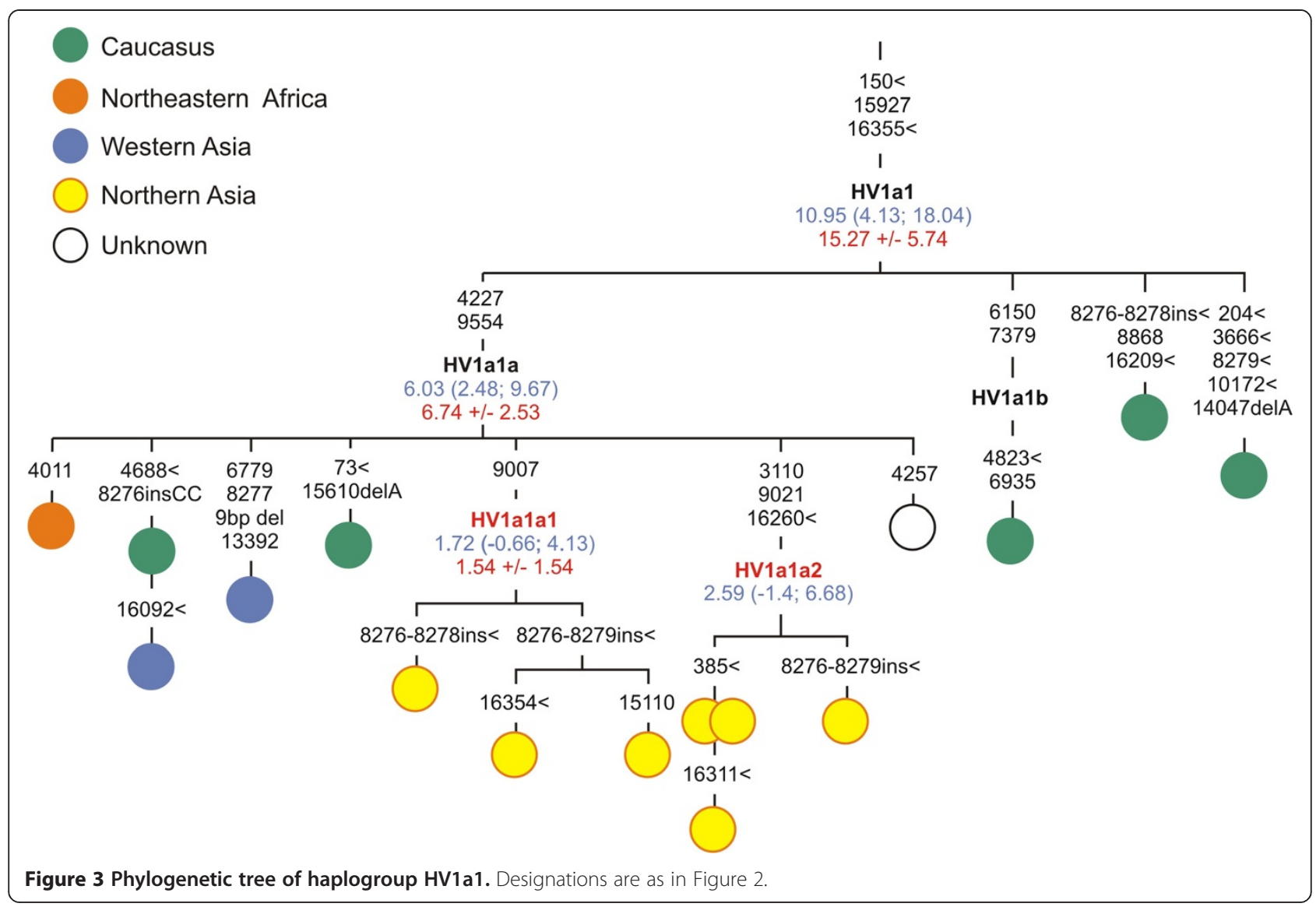

phylogeny [41]. The numerous novel subclades were characterized by more distinct geographical distributions, thus allowing inferences on demographic events that occurred at both regional and continental levels [21-27]. In this study, we aimed to define the exact phylogenetic status of western Eurasian mitogenomes specific for northern Asian populations, which are rather uncommon and not well-represented in the current complete mtDNA data set, and pinpoint the source for those lineages by applying the phylogeographic approach. It has been shown that this kind

Table 1 Age estimates for Siberian-specific western Eurasian mtDNA subclades

\begin{tabular}{llll}
\hline Clade & $\begin{array}{l}\text { No. of } \\
\text { mtDNAs }\end{array}$ & Age estimates in kya & Coding region rate \pm s.e. $^{\mathbf{b}}$ \\
\cline { 3 - 4 } U4b1a4 & 3 & $1.93(-0.25 ; 4.16)$ & 0 \\
U4b1b1 & 4 & $3.71(0.79 ; 6.68)$ & $5.93 \pm 2.55$ \\
U4b3a & 3 & $2.59(-0.34 ; 5.57)$ & $4.61 \pm 2.66$ \\
U4d2a & 3 & $4.33(0.53 ; 8.24)$ & $1.54 \pm 1.54$ \\
H8b1 & 10 & $9.52(2.51 ; 16.82)$ & $5.53 \pm 3.57$ \\
S H8b1a & 7 & $2.96(0.06 ; 5.92)$ & $1.32 \pm 0.93$ \\
> H8b1b & 3 & $3.46(-1.31 ; 8.38)$ & 0 \\
HV1a1a1 & 3 & $1.72(-0.66 ; 4.13)$ & $1.54 \pm 1.54$ \\
HV1a1a2 & 4 & $2.59(-1.4 ; 6.68)$ & 0 \\
J2a2b3 & 4 & $0.64(-0.61 ; 1.91)$ & $1.15 \pm 1.15$ \\
T2g1a1a & 3 & $0.86(-0.82 ; 2.55)$ & 0 \\
X2e2a1 & 5 & $1.55(-0.71 ; 3.83)$ & $2.77 \pm 2.06$ \\
\hline
\end{tabular}

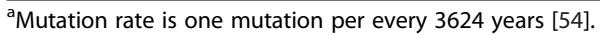

${ }^{\mathrm{b}}$ Mutation rate is one mutation per every 4610 years [55]. 
of analysis can be very powerful, because nesting of particular mitogenomes within clusters from a specific geographical region makes it possible to reveal the origin of those lineages, by applying the parsimony principle $[26,42]$.

Although the genetic heritage of aboriginal Siberians is mostly of eastern Asian ancestry, analyses of autosomal SNP data and uniparental markers show that a substantial western Eurasian component is observed in the majority of northern Asian populations. Thus, the composition of mtDNA lineages of western Eurasian origin revealed in southern Siberian populations suggests that there were at least two migrations into southern Siberia, one from eastern Europe and the other from western Asia/the Caucasus. Traces of both migrations associated with different mtDNA haplogroups were detected in all southern Siberian regional groups, with minor influence on the most northeastern of the eastern Sayan populations [15]. However, the extent to which modern Siberians trace their western Eurasian ancestry to the eastern Europe or to western Asia/Caucasus remains unclear.

Our results, primarily from the detailed analysis of 158 Siberian-specific western Eurasian mtDNA genomes, suggest that nearly $40 \%$ of western Eurasian maternal lineages found in northern Asia trace their ancestry to western Asia, whereas another 30\% most likely have European ancestry. Our analysis shows that at least one of the major Siberian haplogroup $\mathrm{H}$ mtDNA lineages, H8b1, has a deep western Asian ancestry, tracing back at least as far as the early or midHolocene. Furthermore, our results suggest that two newly described southern Siberian haplogroup HV subclades, HV1a1a1 and HV1a1a2, for which western Asian ancestry is also proposed, dated back to late and mid-Holocene, respectively. Despite some uncertainty in its ancestral branching relationship, a western Asian ancestry seems likely for the U4b1b1c subclade found so far in southern (Altaians, Shorians) and western (Mansi) Siberia as well as in Iran and the Volga-Ural region. This subclade dates to 4 4-6 kya, thus suggesting a mid-Holocene radiation in Siberia. Another Siberian specific subclade, X2e2a1, dates to 1.5-3 kya and nests within deeper Near Eastern lineages dating to $\sim 5 \mathrm{kya}$, also suggesting (similarly to U4b1b1c) the mid-Holocene dispersal from Near East to southern Siberia. Aside from this, there is a single highly divergent K1a17b-lineage from Baikal region populations nested within western Asian subclade K1a17, pointing to a gene flow from western Asia to southern Siberia, which might have occurred at the end of LGM but not earlier than 18-21 kya. The phylogenetic nesting patterns suggest that several minor lineages may have been introduced in $\mathrm{Si}$ beria at the same time (with some lost later by drift). Thus for example, U7a2*, HV13a, and N1alb1a1 mtDNAs, with their nesting within preliminary western Asian lineages, were most likely assimilated not earlier than 18.3-24.2 kya, whereas U2e1i southern Siberian founder having a putative Caucasus origin may have been introduced into northern Asia later, 15.8-16.6 kya. In turn, U4a1e, U4a1d, H6a1, HV6, and HV9 mtDNAs with their nesting within preliminary European lineages may have been introduced into northern Asia even later, in the time range from $\sim 9.3$ to $\sim 14.2$ kya.

\section{Conclusions}

Overall, the phylogeographic analysis strongly implies that the western Eurasian founders, giving rise to Siberian specific subclades, trace their ancestry only to the early and mid-Holocene, though some of genetic lineages may trace their ancestry back to the end of LGM. Importantly, we have not found the modern northern Asians to have western Eurasian genetic components of sufficient antiquity to indicate traces of pre-LGM expansions, that originated from the Upper Paleolithic industries present both in the southern Siberia and Siberian Arctic, and that date back to $\sim 30 \mathrm{kya}$, well before the LGM [43-45]. Apparently, the Upper Paleolithic population of northern Asia, whose western Eurasian ancestry was approved recently by complete genome sequencing of 24 kya-old individual from Mal'ta and 17 kya-old individual from Afontova Gora in south-central Siberia, did not leave a genetic mark on the female lineages of modern Siberians. It is probable that the initial population expansion in the southern Siberia region involved maternal lineages other than present now, or that there was a substantial gene flow into the region after the LGM, most probably from eastern Asian sources as have been suggested by Raghavan et al. [7].

Further complete mitogenome and complete genomebased studies of ancient northern Asian specimens will be extremely informative for revealing spatial patterns attributable not only to primary colonization events but also to more-recent migrations.

\section{Methods}

\section{Ethics statement}

The study was approved by the Ethics Committee of the Institute of Biological Problems of the North, Russian Academy of Sciences, Magadan, Russia (statement no. 003/012 from 15 March, 2012). All subjects provided written informed consent for the collection of samples and subsequent analysis.

\section{Mitochondrial genome sequencing}

Out of about 5700 samples of northern, eastern and western Asians as well as Europeans that were screened previously for haplogroup-diagnostic RFLP markers and subjected to control region sequencing (Additional file 6) a total of 166 samples were selected for complete mtDNA 
sequencing (Additional file 7). Samples were selected to include the widest possible range of western Eurasian mtDNA lineages found in Siberian populations as well as some European mtDNAs belonging to sub-haplogroups $\mathrm{U} 2, \mathrm{U} 3, \mathrm{U} 4, \mathrm{U} 8 \mathrm{a}, \mathrm{K}$, and $\mathrm{H}$, which are still underrepresented in the published data sets on complete mtDNA variation. The complete mtDNA sequencing was performed as described in detail by Torroni et al. [46] using an ABI 3130 and ABI 3500xL Genetic Analyzers. DNA sequence data were analyzed using SeqScape 2.5 software (Applied Biosystems) and compared to the revised Cambridge reference sequence (rCRS) [47]. The RSRS [48] was not used in the analysis due to potential errors which it contains as shown by Malyarchuk [49]. Besides, switching to a new reference sequence (from rCRS to RSRS) in the mtDNA studies still has not found an international consensus [50,51].

\section{Statistical analysis and molecular dating}

For reconstruction of the mtDNA phylogenies the data obtained in this study and those published recently $[20,21,26]$ as well as all available at PhyloTree data base [41] were taken into account. A nomenclature, which we hereby update follows [41], with several new modifications. The most-parsimonious trees of the complete mtDNA sequences were reconstructed manually, and verified by means of the Network 4.5.1.0 software [52], and using mtPhyl software (http://eltsov.org), which is designed to reconstruct maximum parsimony phylogenetic trees. Both applications calculate haplogroup divergence estimates (rho) and their error ranges, as average number of substitutions in mtDNA clusters (haplogroups) from the ancestral sequence type [53]. Values of mutation rates based on mtDNA complete genome variability data (one mutation every 3624 years [54] and coding region substitutions (one mutation every 4610 years [55]) were used. Nucleotide position (np) 16519 as well as positions showing point indels and/or transversions located between nps 16180-16193, 303$315,522-524,573-576$ were excluded from the phylogenetic analysis.

\section{Availability of supporting data}

The data set supporting the results of this article is included within the article and its additional files. The 166 novel complete mtDNA sequences supporting the results of this article are available in the National Center for Biotechnology Information (Genbank) under accession numbers KJ856675-KJ856840, http://www. ncbi.nlm.nih.gov/Genbank/. The assignment of all samples to their sequence accession numbers is listed in Additional file 7.

\section{Additional files}

\begin{abstract}
Additional file 1: Western Eurasian mtDNA haplogroup frequencies in northern Asian populations (\%).

Additional file 2: Map showing the locations of the northern Asian populations divided into seven regional groups color coded as: northeastern Siberia - blue, western Siberia - red, central Siberia green, Altai region of southern Siberia - orange, eastern Sayan region of southern Siberia - green mint, Baikal region of southern Siberia - yellow, Okhotsk/Amur region of southern Siberia - purple. The total frequency (\%) of western Eurasian mtDNA lineages in each population is given in circles.
\end{abstract}

Additional file 3: Maximum-parsimony phylogenetic tree of 158 complete mtDNA sequences, constructed using the program mtPhyl. Numbers along links refer to substitutions scored relative to the rCRS (Andrews et al. [47]). Transversions are further specified; ins and del denote insertions and deletions of nucleotides, respectively; back mutations are underlined; symbol < denotes parallel mutations; heteroplasmies are labeled using the IUPAC code. For phylogeny reconstruction, the length variation in the poly-C stretches at nps 303-315 and 16184-16194 was not used. Polymorphism at np 16519 and A-C transversions at nps 16182 and 16183 were excluded. Samples labeled as in Additional file 4 and Additional file 7 and newly sequenced samples are marked in red. Established haplogroup labels are shown in black; blue are redefined and red are newly identified haplogroups in the present study.

Additional file 4: Population origin, haplogroup affiliation, specificity and putative origin of western Eurasian northern Asian mitogenomes.

Additional file 5: Maximum-parsimony phylogenetic trees of complete mtDNA sequences belonging to haplogroups $U 1 a, U 7$, U2e, U3, U4, U5a2a, U5b1b1a, U8a, K1a, K1a17, K1b2, K2a3, K2a5, H11, H15, H20, H8, H49, H7c, H97, JT, HV, N1a1, W3, and X2e2, constructed using the program mtPhyl. Numbers along links refer to substitutions scored relative to rCRS (Andrews et al. [47]). Transversions are further specified; ins and del denote insertions and deletions of nucleotides, respectively; back mutations are underlined; symbol < denotes parallel mutation; heteroplasmies are labeled using the IUPAC code. Newly sequenced Siberian (marked in yellow) and European (marked in green) samples labeled as in Additional file 4 and Additional file 7, for published data the accession number in indicated. Coalescence time estimates expressed in kya are shown along links next to clade labels and were calculated by computing the averaged distance (rho) and the standard error (s) (Saillard et al. [53]). Calculations were obtained using the entire mtDNA genomes but excluding the length variation in the poly-C stretches at nps 303-315 and 16184-16194 and hot spot mutations such as 16182C, 16183C, and 16519. Values of mutation rates based on mtDNA complete genome variability data (Soares et al. [54]; marked in blue) and coding region substitutions (Perego et al. [55]; marked in red) were used. Established haplogroup labels are shown in black; blue are redefined and red are newly identified haplogroups in the present study.

Additional file 6: List of population samples subjected previously for haplogroup-diagnostic RFLP screening and control region sequencing from where 166 samples were selected for complete mtDNA sequencing.

Additional file 7: Origin and sub-haplogroup affiliation of complete mtDNAs sequenced in this study.

Competing interests

The authors declare that they have no competing interests.

Authors' contributions

$M D$ and BM conceived and designed the study. MD, BM, ID, TG, IT and IZ contributed reagents/materials/analysis tools. MD, GD, MP, AL, UR and KS performed the experiments. MD, BM and TG analyzed the data. MD and BM wrote the manuscript. All authors read and approved the final manuscript. 


\section{Acknowledgments}

We are grateful to all the donors for providing biological specimens and thank Dr. Tomas Vanecek (Charles University, Pilsen, Czech Republic) for some DNA samples and Denis Aleksandrov (Institute of Biological Problems of the North, Magadan, Russia) for technical assistance. This study was supported by grants from the Presidium of Russian Academy of Sciences (12-I-P30-12) (to BM), the Far-Eastern Branch of the Russian Academy of Sciences (12-III-A-06-101) (to MD), the Russian Foundation for Basic Research (14-04-00131) (to BM) and the Polish Ministry of Science and Higher Education (N301 075839).

\section{Author details}

${ }^{1}$ Institute of Biological Problems of the North, Russian Academy of Sciences, Magadan, Russia. ${ }^{2}$ Ludwik Rydygier Collegium Medicum, Institute of Forensic Medicine, Department of Molecular and Forensic Genetics, The Nicolaus Copernicus University, Bydgoszcz, Poland. Institute of General and Experimental Biology, Russian Academy of Sciences, Ulan-Ude, Russia. ${ }^{4}$ Scientific and Practical Centre of the State Committee of Forensic Expertises, Minsk, Belarus. ${ }^{5}$ Vavilov Institute of General Genetics, Russian Academy of Sciences, Moscow, Russia.

Received: 22 May 2014 Accepted: 29 September 2014

Published online: 10 October 2014

\section{References}

1. Okladnikov AP: Ancient Population of Siberia and its Cultures. Cambridge, MA: Peabody Museum; 1959.

2. Okladnikov AP: Ancient Population of Siberia and its Cultures. In The Peoples of Siberia. Edited by Levin MG, Potapov LP. Chicago: University of Chicago Press; 1964:13-98.

3. Alekseev V: The Physical Specificities of Paleolithic Hominids in Siberia. In The Paleolithic of Siberia. Edited by Derev'anko A. Urbana: University of Illinois Press; 1998:122-136.

4. Medvedev G: Upper Paleolithic Sites in South-Central Siberia. In The Paleolithic of Siberia: New Discoveries and Interpretations. Edited by Derev'anko AP, Shimkin DB, Powers WR. Urbana: University of Illinois Press; 1998:122-137.

5. Medvedev G, Cauwe N, Vorob'eva G, Coupe D, Claes L, Lepnina E, Modrie S, Mukharramov S, Osadchy S, Pettitte P, Rebrikov P, Rogovsky E, Sitlivyi V, Sulerzhitsky L, Khenzykhenova D: The Malta Paleolithic locality (in Russian). Irkutsk: ARCOM Press; 1996

6. Alexeev VP, Gohman II: Anthropology of Asiatic part of the USSR (in Russian) Moscow: Nauka; 1984.

7. Raghavan M, Skoglund P, Graf KE, Metspalu M, Albrechtsen A, Moltke I, Rasmussen S, Stafford TW Jr, Orlando L, Metspalu E, Karmin M, Tambets K, Rootsi S, Mägi R, Campos PF, Balanovska E, Balanovsky O, Khusnutdinova E, Litvinov S, Osipova LP, Fedorova SA, Voevoda MI, DeGiorgio M, Sicheritz-Ponten T, Brunak S, Demeshchenko S, Kivisild T, Villems R, Nielsen R, Jakobsson M, et al: Upper palaeolithic Siberian genome reveals dual ancestry of native Americans. Nature 2014, 505:87-91.

8. Mooder KP, Schurr TG, Bamforth FJ, Bazaliiski VI, Savel'ev NA: Population affinities of neolithic Siberians: a snapshot from prehistoric Lake Baikal. Am J Phys Anthropol 2006, 129:349-361.

9. Keyser C, Romac S, Bouakaze C, Amory S, Crubézy E, Ludes B: Tracing back ancient south Siberian population history using mitochondrial and Y-chromosome SNPs. Forensic Sci Int Gene Supp/ Series 2008, 1:343-345.

10. Keyser C, Bouakaze C, Crubézy E, Nikolaev VG, Montagnon D, Reis T, Ludes B: Ancient DNA provides new insights into the history of south Siberian Kurgan people. Hum Genet 2009, 126:395-410.

11. González-Ruiz M, Santos C, Jordana X, Simón M, Lalueza-Fox C, Gigli E, Aluja MP, Malgosa A: Tracing the origin of the east-west population admixture in the Altai region (Central Asia). PLoS One 2012, 7:e48904.

12. Rasmussen M, Li Y, Lindgreen S, Pedersen JS, Albrechtsen A, Moltke I, Metspalu M, Metspalu E, Kivisild T, Gupta R, Bertalan M, Nielsen K, Gilbert MT, Wang Y, Raghavan M, Campos PF, Kamp HM, Wilson AS, Gledhill A, Tridico S, Bunce M, Lorenzen ED, Binladen J, Guo X, Zhao J, Zhang X, Zhang $\mathrm{H}, \mathrm{Li}$ Z, Chen M, Orlando L, et al: Ancient human genome sequence of an extinct Palaeo-Eskimo. Nature 2010, 463:757-762.

13. Fedorova SA, Reidla M, Metspalu E, Metspalu M, Rootsi S, Tambets K, Trofimova N, Zhadanov SI, Hooshiar Kashani B, Olivieri A, Voevoda MI, Osipova LP, Platonov FA, Tomsky Ml, Khusnutdinova EK, Torroni A, Villems R: Autosomal and uniparental portraits of the native populations of Sakha (Yakutia): implications for the peopling of northeast Eurasia. BMC Evol Biol 2013, 13:127.

14. Cardona A, Pagani L, Antao T, Lawson DJ, Eichstaedt CA, Yngvadottir B, Shwe MT, Wee J, Romero IG, Raj S, Metspalu M, Villems R, Willerslev E, Tyler-Smith C, Malyarchuk BA, Derenko MV, Kivisild T: Genome-wide analysis of cold adaption in indigenous Siberian populations. PLoS One 2014, 9:e98076

15. Derenko M, Malyarchuk B, Grzybowski T, Denisova G, Dambueva I, Perkova M, Dorzhu C, Luzina F, Lee HK, Vanecek T, Villems R, Zakharov I: Phylogeographic analysis of mitochondrial DNA in northern Asian populations. Am J Hum Genet 2007, 81:1025-1041.

16. Volodko NV, Starikovskaya EB, Mazunin IO, Eltsov NP, Naidenko PV, Wallace DC, Sukernik RI: Mitochondrial genome diversity in arctic Siberians, with particular reference to the evolutionary history of Beringia and Pleistocenic peopling of the Americas. Am J Hum Genet 2008, 82:1084-1100.

17. Derenko M, Malyarchuk B, Grzybowski T, Denisova G, Rogalla U, Perkova M, Dambueva I, Zakharov I: Origin and post-glacial dispersal of mitochondrial DNA haplogroups C and D in northern Asia. PLoS One 2010, 5:e15214.

18. Derenko M, Malyarchuk B, Denisova G, Perkova M, Rogalla U, Grzybowski T, Khusnutdinova E, Dambueva I, Zakharov I: Complete mitochondrial DNA analysis of eastern Eurasian haplogroups rarely found in populations of northern Asia and eastern Europe. PLoS One 2012, 7:e32179.

19. Sukernik RI, Volodko NV, Mazunin IO, Eltsov NP, Dryomov SV, Starikovskaya EB: Mitochondrial genome diversity in the Tubalar, Even, and Ulchi: contribution to prehistory of native Siberians and their affinities to native Americans. Am J Phys Anthropol 2012, 148:123-138.

20. Duggan AT, Whitten M, Wiebe V, Crawford M, Butthof A, Spitsyn V, Makarov S, Novgorodov I, Osakovsky V, Pakendorf B: Investigating the prehistory of Tungusic peoples of Siberia and the Amur-Ussuri region with complete mtDNA genome sequences and Y-chromosomal markers. PLoS One 2013, 8:e83570.

21. Derenko M, Malyarchuk B, Bahmanimehr A, Denisova G, Perkova M, Farjadian S, Yepiskoposyan L: Complete mitochondrial DNA diversity in Iranians. PLoS One 2013, 8:e80673.

22. Malyarchuk B, Grzybowski T, Derenko M, Perkova M, Vanecek T, Lazur J, Gomolcak P, Tsybovsky I: Mitochondrial DNA phylogeny in eastern and western Slavs. Mol Biol Evol 2008, 25:1651-1658.

23. Malyarchuk B, Derenko M, Grzybowski T, Perkova M, Rogalla U, Vanecek T, Tsybovsky I: The peopling of Europe from the mitochondrial haplogroup U5 perspective. PLoS One 2010, 5:e10285.

24. Fernandes V, Alshamali F, Alves M, Costa MD, Pereira JB, Silva NM, Cherni L, Harich N, Cerny V, Soares P, Richards MB, Pereira L: The Arabian cradle: mitochondrial relicts of the first steps along the southern route out of Africa. Am J Hum Genet 2012, 90:347-355.

25. Pala M, Olivieri A, Achilli A, Accetturo M, Metspalu E, Reidla M, Tamm E, Karmin M, Reisberg T, Hooshiar Kashani B, Perego UA, Carossa V, Gandini F, Pereira JB, Soares P, Angerhofer N, Rychkov S, Al-Zahery N, Carelli V, Sanati MH, Houshmand M, Hatina J, Macaulay V, Pereira L, Woodward SR, Davies W, Gamble C, Baird D, Semino O, Villems R, et al: Mitochondrial DNA signals of late glacial recolonization of Europe from near eastern refugia. Am J Hum Genet 2012, 90:915-924.

26. Costa MD, Pereira JB, Pala M, Fernandes V, Olivieri A, Achilli A, Perego UA, Rychkov S, Naumova O, Hatina J, Woodward SR, Eng KK, Macaulay V, Carr M, Soares P, Pereira L, Richards MB: A substantial prehistoric European ancestry amongst Ashkenazi maternal lineages. Nat Commun 2013, 4:2543.

27. Olivieri A, Pala M, Gandini F, Hooshiar Kashani B, Perego UA, Woodward SR, Grugni V, Battaglia V, Semino O, Achilli A, Richards MB, Torroni A: Mitogenomes from two uncommon haplogroups mark late glacial/ postglacial expansions from the Near East and neolithic dispersals within Europe. PLoS One 2013, 8:e70492.

28. Derbeneva OA, Starikovskaia EB, Volod'ko NV, Wallace DC, Sukernik Rl: Mitochondrial DNA variation in Kets and Nganasans and the early peoples of northern Eurasia. Genetika 2002, 38:1554-1560.

29. Pimenoff VN, Comas D, Palo JU, Vershubsky G, Kozlov A, Sajantila A: Northwest Siberian Khanty and Mansi in the junction of west and east Eurasian gene pools as revealed by uniparental markers. Eur J Hum Genet 2008, 16:1254-1264.

30. Achilli A, Olivieri A, Pala M, Metspalu E, Fornarino S, Battaglia V, Accetturo M, Kutuev I, Khusnutdinova E, Pennarun E, Cerutti N, Di Gaetano C, Crobu F, 
Palli D, Matullo G, Santachiara-Benerecetti AS, Cavalli-Sforza LL, Semino O, Villems R, Bandelt HJ, Piazza A, Torroni A: Mitochondrial DNA variation of modern Tuscans supports the near eastern origin of Etruscans. Am J Hum Genet 2007, 80:759-768.

31. Derenko MV, Grzybowski T, Malyarchuk BA, Dambueva IK, Denisova GA, Czarny J, Dorzhu CM, Kakpakov VT, Miścicka-Sliwka D, Woźniak M, Zakharov IA: Diversity of mitochondrial DNA lineages in south Siberia. Ann Hum Genet 2003, 67:391-411.

32. Dulik MC, Zhadanov SI, Osipova LP, Askapuli A, Gau L, Gokcumen O, Rubinstein S, Schurr TG: Mitochondrial DNA and Y chromosome variation provides evidence for a recent common ancestry between native Americans and Indigenous Altaians. Am J Hum Genet 2012, 90:229-246.

33. Richards M, Macaulay V, Hickey E, Vega E, Sykes B, Guida V, Rengo C, Sellitto D, Cruciani F, Kivisild T, Villems R, Thomas M, Rychkov S, Rychkov O, Rychkov Y, Gölge M, Dimitrov D, Hill E, Bradley D, Romano V, Calì F, Vona G, Demaine A, Papiha S, Triantaphyllidis C, Stefanescu G, Hatina J, Belledi M, Di Rienzo A, Novelletto A, et al: Tracing European founder lineages in the near eastern mtDNA pool. Am J Hum Genet 2000, 67:1251-1276.

34. Bogotova Zl: An Investigation of the Genetic Structure of Kabardinian and Balkars. In PhD thesis. Ufa: Institute of Biochemistry and Genetics; 2009.

35. Bermisheva M, Tambets K, Villems R, Khusnutdinova E: Diversity of mitochondrial DNA haplotypes in ethnic populations of the Volga-Ural region of Russia. Mol Biol (Mosk) 2002, 36:990-1001.

36. Malyarchuk BA, Grzybowski T, Derenko MV, Czarny J, Woźniak M, Miścicka-Sliwka D: Mitochondrial DNA variability in Poles and Russians. Ann Hum Genet 2002, 66:261-283.

37. Naumova OY, Rychkov SY, Zhukova OV: Mitochondrial DNA variability in populations and ethnic groups of Tatars of the Tobol-Irtysh basin. Genetika 2009, 45:1260-1269.

38. Starikovskaya EB, Sukernik RI, Derbeneva OA, Volodko NV, Ruiz-Pesini E, Torroni A, Brown MD, Lott MT, Hosseini SH, Huoponen K, Wallace DC: Mitochondrial DNA diversity in indigenous populations of the southern extent of Siberia, and the origins of Native American haplogroups. Ann Hum Genet 2005, 69:67-89.

39. Roostalu U, Kutuev I, Loogväli EL, Metspalu E, Tambets K, Reidla M, Khusnutdinova EK, Usanga E, Kivisild T, Villems R: Origin and expansion of haplogroup $\mathrm{H}$, the dominant human mitochondrial DNA lineage in west Eurasia: the near eastern and Caucasian perspective. Mol Biol Evol 2007. 24:436-448.

40. Palanichamy MG, Zhang CL, Mitra B, Malyarchuk B, Derenko M, Chaudhuri TK, Zhang YP: Mitochondrial haplogroup N1a phylogeography, with implication to the origin of European farmers. BMC Evol Biol 2010, 10:304

41. van Oven M, Kayser M: Updated comprehensive phylogenetic tree of global human mitochondrial DNA variation. Hum Mutat 2009, 30:386-394.

42. Behar DM, Harmant C, Manry J, van Oven M, Haak W, Martinez-Cruz B, Salaberria J, Oyharçabal B, Bauduer F, Comas D, Quintana-Murci L, Genographic Consortium: The Basque paradigm: genetic evidence of a maternal continuity in the Franco-Cantabrian region since pre-Neolithic times. Am J Hum Genet 2012, 90:486-493.

43. Laukhin SA: A conception of step-by-step peopling of northern Asia by paleolithic humans. Dokl Akad Nauk 1993, 332:352-356.

44. Vasiliev SA: The upper paleolithic of northern Asia. Curr Anthropol 1993 34:82-92

45. Pitulko W, Nikolsky PA, Girya EY, Basilyan AE, Tumskoy VE, Koulakov SA Astakhov SN, Pavlova EY, Anisimov MA: The Yana RHS site: humans in the arctic before the last glacial maximum. Science 2004, 303:52-56.

46. Torroni A, Rengo C, Guida V, Cruciani F, Sellitto D, Coppa A, Calderon FL, Simionati B, Valle G, Richards M, Macaulay V, Scozzari R: Do the four clades of the mtDNA haplogroup L2 evolve at different rates? Am J Hum Genet 2001, 69:1348-1356.

47. Andrews RM, Kubacka I, Chinnery PF, Lightowlers RN, Turnbull DM, Howell N: Reanalysis and revision of the Cambridge reference sequence for human mitochondrial DNA. Nat Genet 1999, 23:147.

48. Behar DM, van Oven M, Rosset S, Metspalu M, Loogväli EL, Silva NM, Kivisild T, Torroni A, Villems R: A "Copernican" reassessment of the human mitochondrial DNA tree from its root. Am J Hum Genet 2012, 90:675-684.

49. Malyarchuk BA: Improving the reconstructed sapiens reference sequence of mitochondrial DNA. Forensic Sci Int Genet 2013, 7:e74-e75.

50. Salas A, Coble M, Desmyter S, Grzybowski T, Gusmão L, Hohoff C, Holland MM, Irwin JA, Kupiec T, Lee HY, Ludes B, Lutz-Bonengel S, Melton T, Parsons TJ, Pfeiffer H, Prieto L, Tagliabracci A, Parson W: A cautionary note on switching mitochondrial DNA reference sequences in forensic genetics. Forensic Sci Int Genet 2012, 6:e182-e184.

51. Bandelt HJ, Kloss-Brandstätter A, Richards MB, Yao YG, Logan I: The case for the continuing use of the revised Cambridge Reference Sequence ( $\mathrm{rCRS}$ ) and the standardization of notation in human mitochondrial DNA studies. J Hum Genet 2014, 59:66-77.

52. Bandelt $H J$, Forster $P$, Röhl A: Median-joining networks for inferring intraspecific phylogenies. Mol Biol Evol 1999, 16:37-48.

53. Saillard J, Forster P, Lynnerup N, Bandelt HJ, Nørby S: mtDNA variation among Greenland Eskimos: the edge of the Beringian expansion. Am J Hum Genet 2000, 67:718-726.

54. Soares P, Ermini L, Thomson N, Mormina M, Rito T, Röhl A, Salas A, Oppenheimer S, Macaulay V, Richards MB: Correcting for purifying selection: an improved human mitochondrial molecular clock. Am J Hum Genet 2009, 84:740-759.

55. Perego UA, Achilli A, Angerhofer N, Accetturo M, Pala M, Olivieri A, Hooshiar Kashani B, Ritchie KH, Scozzari R, Kong QP, Myres NM, Salas A, Semino O, Bandelt HJ, Woodward SR, Torroni A: Distinctive Paleo-Indian migration routes from Beringia marked by two rare mtDNA haplogroups. Curr Biol 2009 , 19:1-8.

\section{doi:10.1186/s12862-014-0217-9}

Cite this article as: Derenko et al.: Western Eurasian ancestry in modern Siberians based on mitogenomic data. BMC Evolutionary Biology $201414: 217$

\section{Submit your next manuscript to BioMed Central and take full advantage of:}

- Convenient online submission

- Thorough peer review

- No space constraints or color figure charges

- Immediate publication on acceptance

- Inclusion in PubMed, CAS, Scopus and Google Scholar

- Research which is freely available for redistribution 